\title{
ПЕРВИЧНАЯ ИНВАЛИДНОСТЬ ВЗРОСЛОГО НАСЕЛЕНИЯ АЛТАЙСКОГО КРАЯ ВСЛЕДСТВИЕ ПСИХИЧЕСКИХ РАССТРОЙСТВ
}

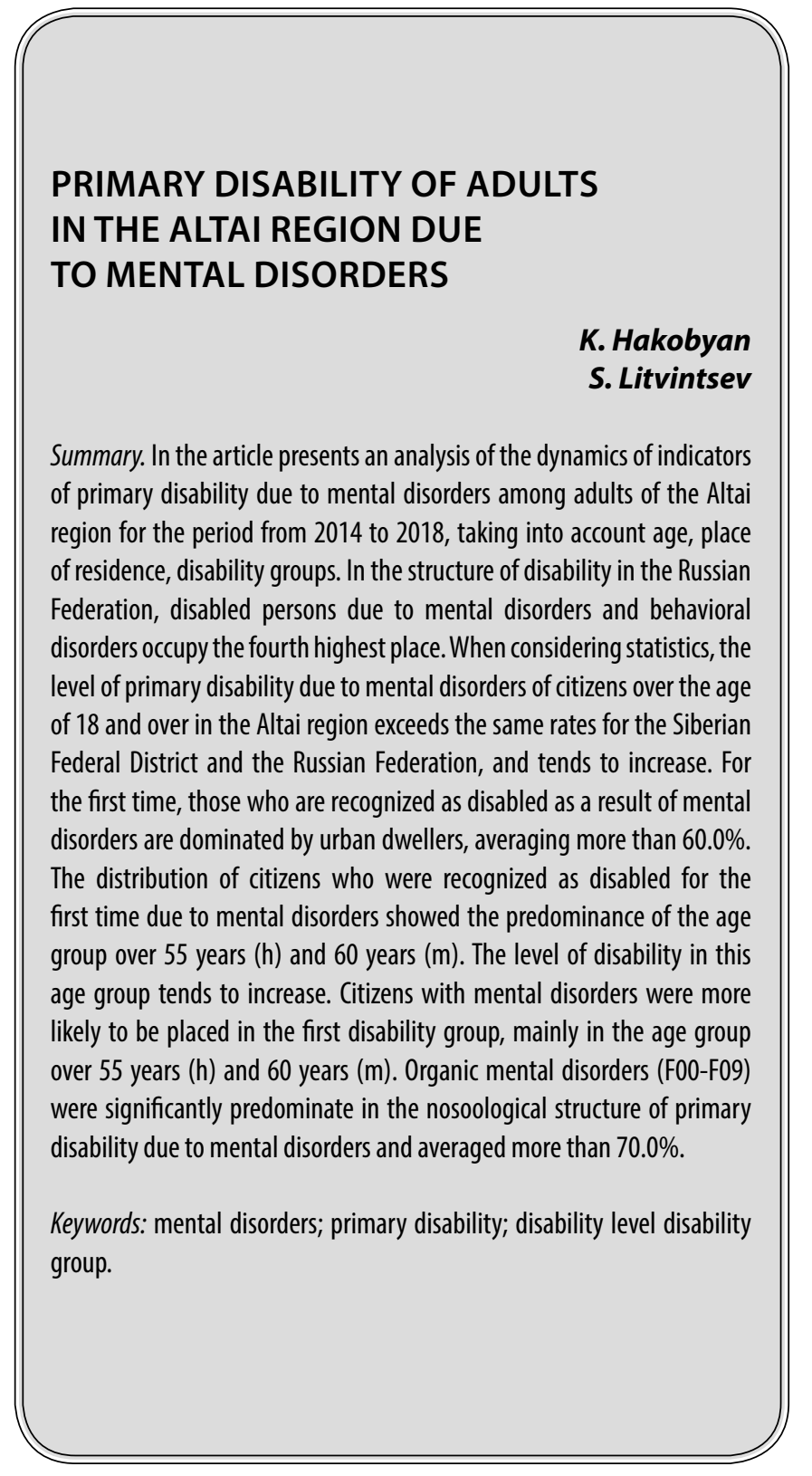

$\Pi$ роблема охраны психического здоровья существует во всех государствах. Психическое здоровье считается не только частью, но в определенной степени и базисным элементом общего здоровья. Ухудшение психического здоровья нации расценивается как основной показатель неблагополучия общества. Общегосударственная значимость этой проблемы определяется трудовыми потерями и значительной инвалидизацией, вызываемыми расстройствами психики $[2,14]$.
Акопян Кристина Сетраковна Aсnирант, ФГБОУ ДПО «Санкт-Петербургский институт усовершенствования врачей экспертов» Министерства труда и сочиальной защиты Российской Федерачии; врач по медико-сочиальной экспертизе, nсихиатр, ФКУ «Главное бюро медико-социальной экспертизы по Алтайскому краю» Минтруда России

mse22sostav5@mail.ru

Литвинцев Сергей Викторович

Д.м.н., профессор, ФГБОУ ДПО «Санкт-Петербургский институт усовершенствования врачей-экспертов» Министерства труда и социальной защиты Российской Федерачиu

Аннотация. В статье представлен анализ динамики показателей первичной инвалидности вследствие психических расстройств среди взрослого населения Алтайского края за период с 2014 г. по 2018 г. с учетом возраста, места жительства, групп инвалидности. В структуре инвалидности в Российской Федерации инвалиды вследствие психических расстройств и расстройств поведения занимают четвертое ранговое место. При рассмотрении статистических данных уровень первичной инвалидности вследствие психических расстройств граждан в возрасте старше 18 лет и старше в Алтайском крае превышает аналогичные показатели по Сибирскому Федеральному округу и Российской Федерации, и имеет тенденцию к увеличению. Среди впервые признанных инвалидами вследствие психических расстройств преобладают городские жители и составляют в среднем более $60,0 \%$. Распределение граждан, впервые признанных инвалидами вследствие психических расстройств, по возрасту показало преобладание возрастной группы старше 55 лет (ж) и 60 лет (м). Уровень инвалидности в данной возрастной группе имеет тенденцию к увеличению. Гражданам с психическими расстройствами чаще устанавливалась первая группа инвалидности, преимущественно в возрастной группе старше 55 лет (ж) и 60 лет (м). В нозологической структуре первичной инвалидности вследствие психических расстройств значительно преобладали органические психические расстройства (F00-F09) и составляли в среднем более 70,0\%.

Ключевые слова: психические расстройства; первичная инвалидность; уровень инвалидности; группа инвалидности.

Показатели инвалидности и их динамика являются одной из основных характеристик общественного здоровья, уровня социально-экономического развития общества, демографического благополучия, эффективности системы здравоохранения и медико-социальной реабилитации $[1,3,9,15]$.

В структуре инвалидности по классам болезней в Российской Федерации инвалиды вследствие психи- 
Таблица 1. Динамика уровня первичной инвалидности вследствие психических расстройств среди взрослого населения Алтайского края в сравнении с показателями СФО и РФ (на 10000 соответствующего населения)

\begin{tabular}{|l|l|l|l|}
\hline Годы & Алтайский край & Сибирский Федеральный округ & Российская Федерация \\
\hline 2014 & 2,9 & 3,0 & 2,7 \\
\hline 2015 & 3,4 & 2,9 & 2,7 \\
\hline 2016 & 3,6 & 3,2 & 2,7 \\
\hline 2017 & 3,8 & 3,1 & 2,9 \\
\hline 2018 & 3,5 & 3,1 & 2,7 \\
\hline
\end{tabular}

Таблица 2. Распределение граждан в возрасте 18 лет и старше, впервые признанных инвалидами вследствие психических расстройств, по месту жительства

\begin{tabular}{|c|c|c|c|c|c|}
\hline \multirow{2}{*}{ Годы } & \multirow{2}{*}{$\begin{array}{l}\text { Всего впервые признано } \\
\text { инвалидами, абс. }\end{array}$} & \multicolumn{2}{|c|}{ Городские жители } & \multicolumn{2}{|c|}{$\begin{array}{l}\text { Сельские } \\
\text { жители }\end{array}$} \\
\hline & & абс. & $\%$ & aбc. & $\%$ \\
\hline 2014 & 557 & 344 & 61,8 & 213 & 38,2 \\
\hline 2015 & 649 & 437 & 67,3 & 212 & 32,7 \\
\hline 2016 & 676 & 423 & 62,6 & 253 & 37,4 \\
\hline 2017 & 716 & 444 & 62,0 & 272 & 38,0 \\
\hline 2018 & 658 & 412 & 62,6 & 246 & 37,4 \\
\hline
\end{tabular}

Таблица 3. Распределение граждан в возрасте 18 лет и старше, впервые признанных инвалидами вследствие психических расстройств, по возрасту

\begin{tabular}{|c|c|c|c|c|c|c|c|}
\hline \multirow{2}{*}{ Годы } & \multirow{2}{*}{$\begin{array}{l}\text { Всего впервые } \\
\text { признано } \\
\text { инвалидами, абс. }\end{array}$} & \multicolumn{2}{|c|}{ От 18 до 44 лет } & \multicolumn{2}{|c|}{$\begin{array}{l}\text { От } 45 \text { до } 54 \text { лет (ж), от } 45 \\
\text { до } 59 \text { лет (м) }\end{array}$} & \multicolumn{2}{|c|}{$\begin{array}{l}\text { От } 55 \text { лет (ж) и } 60 \text { лет (м) } \\
\text { и старше }\end{array}$} \\
\hline & & абс. & $\%$ & абс. & $\%$ & aбc. & $\%$ \\
\hline 2014 & 557 & 200 & 35,9 & 120 & 21,5 & 237 & 42,6 \\
\hline 2015 & 649 & 195 & 30,0 & 96 & 14,8 & 358 & 55,2 \\
\hline 2016 & 676 & 230 & 34,0 & 117 & 17,3 & 329 & 48,7 \\
\hline 2017 & 716 & 172 & 24,0 & 104 & 14,5 & 440 & 61,5 \\
\hline 2018 & 658 & 141 & 21,4 & 96 & 14,6 & 421 & 64,0 \\
\hline
\end{tabular}




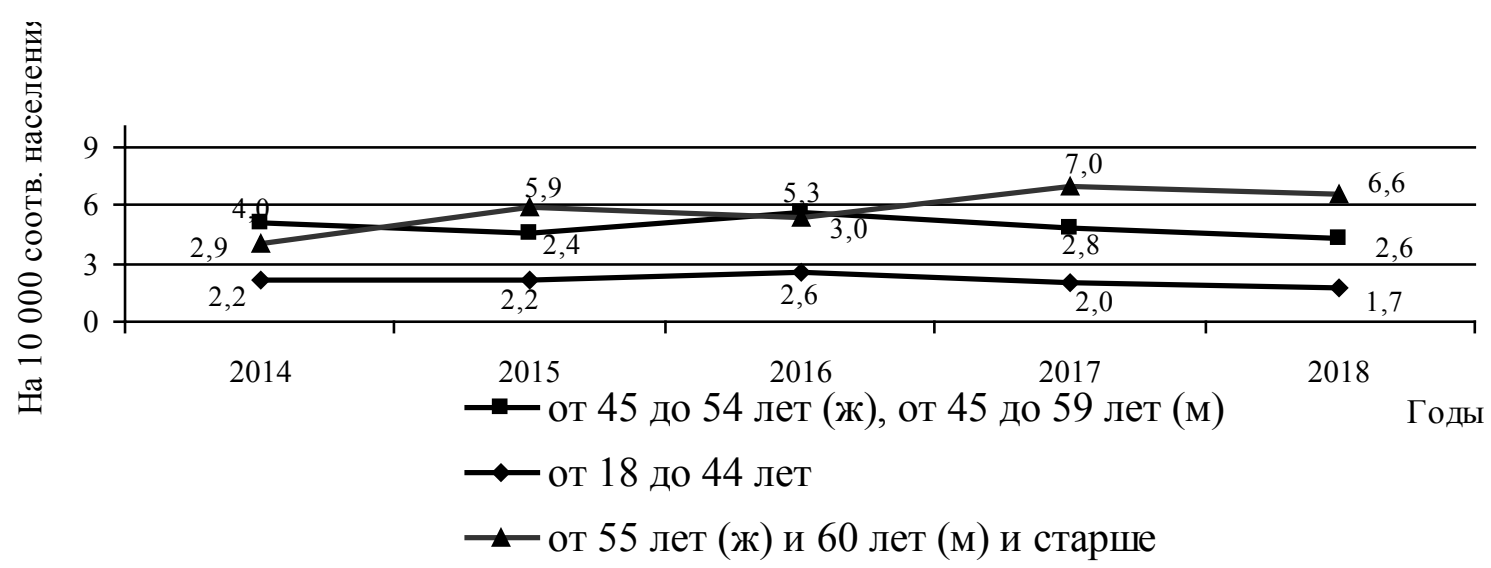

Рис. 1. Динамика уровня первичной инвалидности вследствие психических расстройств в зависимости от возраста (на 10000 соответствующего населения)

ческих расстройств и расстройств поведения занимают четвертое ранговое место с удельным весом 5,0-4,9\% в 2017-2018 гг. [8].

Несмотря на большое число публикаций, исследований инвалидности взрослого населения вследствие психических расстройств в Алтайском крае не проводилось, что обусловливает актуальность данного исследования.

\section{Цель исслеАования}

Изучить динамику основных показателей первичной инвалидности вследствие психических расстройств среди взрослого населения Алтайского края.

\section{Материалы и методы}

При проведении исследования использовались статистические данные Федерального казенного учреждения «Главное бюро медико-социальной экспертизы по Алтайскому краю» Министерства труда и социальной защиты Российской Федерации. Материалом исследования явились отчетные формы № 7 (собес). Период исследования составлял 2014-2018 гг. Методы исследования: статистический (рассчитывались экстенсивные, интенсивные показатели), аналитический.

\section{Результаты \\ исслеАования}

В нозологической структуре первичной инвалидности взрослого населения Алтайского края, как и в целом В Российской Федерации, психические расстройства и расстройства поведения занимают четвертое ранговое место после злокачественных новообразований, болезней системы кровообращения, болезней костно-мышечной системы и соединительной ткани. Доля инвалидов вследствие психических расстройств на фоне снижения общего числа впервые признанных инвалидами в крае имеет тенденцию к увеличению и превышает аналогичный показатель по Российской Федерации. В 2014 г. всего впервые признано инвалидами в крае 11066 граждан старше 18 лет, из них вследствие психических расстройств - 557, что составило 5,0\%, в 2015 г. всего впервые признано инвалидами 11657, из них вследствие психических расстройств - 649 (5,6\%), в 2016 г.- 11009 и 676 (6,1\%), в 2017 г.- 11034 и 716 (6,5\%), в 2018 г.10991 и 658 (6,0\%) соответственно.

Уровень первичной инвалидности вследствие психических расстройств среди взрослого населения в Алтайском крае за период исследования превышал аналогичные показатели по Российской Федерации и Сибирскому Федеральному округу [5-8] и имел тенденцию к увеличению с 2,9 в 2014 г. до 3,5 на 10000 взрослого населения в 2018 г. (табл. 1).

Заболеваемость взрослого населения Алтайского края психическими расстройствами превышает аналогичные показатели по Российской Федерации более чем в 1,5 раза и составила в 2014 г.- 7992,02 (в РФ 4962,70), в 2015 г.-8083,71 (в РФ - 4763, 60), в 2016 г.7872,41 (в РФ-4605,7), в 2017 г. - 7271,4 (в РФ-4437,4), в 2018 г.-6698, 4 (в РФ-нет данных) на 100000 населения старше 18 лет Федерации. Заболеваемость взрослого населения Алтайского края психическими расстройствами, в том числе с диагнозом, установленным впервые в жизни, более чем в 2,5 раза превышала аналогичные показатели по Российской Федерации и составляла в 2014 г.- 1306,22 (в РФ - 466,0), в 2015 г.1336,47 (РФ - 451,30), в 2016 г.- 1173,82 (в РФ - 407,20), в 2017 г. - 1067,00 (РФ - 377,30), в 2018 г.- 1110,28 (в РФ-нет данных) на 100000 населения старше 18 лет [10-13]. 
Таблица 4. Распределение граждан в возрасте 18 лет и старше, впервые признанных инвалидами вследствие психических расстройств, по полу

\begin{tabular}{|c|c|c|c|c|c|}
\hline \multirow{3}{*}{ Годы } & \multirow{3}{*}{$\begin{array}{l}\text { Всего впервые признано } \\
\text { инвалидами, абс. }\end{array}$} & \multicolumn{4}{|c|}{ Из них } \\
\hline & & \multicolumn{2}{|c|}{ Мужчины } & \multicolumn{2}{|c|}{ Женщины } \\
\hline & & a6c. & $\%$ & aбc. & $\%$ \\
\hline 2014 & 557 & 299 & 53,7 & 258 & 46,3 \\
\hline 2015 & 649 & 300 & 46,2 & 349 & 53,8 \\
\hline 2016 & 676 & 346 & 51,2 & 330 & 48,8 \\
\hline 2017 & 716 & 347 & 48,5 & 369 & 51,5 \\
\hline 2018 & 658 & 292 & 44,4 & 366 & 55,6 \\
\hline
\end{tabular}

Таблица 5. Распределение граждан в возрасте 18 лет и старше, впервые признанных инвалидами вследствие психических расстройств, по группам инвалидности

\begin{tabular}{|c|c|c|c|c|c|c|c|}
\hline \multirow[t]{2}{*}{ Годы } & \multirow{2}{*}{$\begin{array}{l}\text { Всего впервые } \\
\text { признано инвалидами, } \\
\text { абс. }\end{array}$} & \multicolumn{2}{|c|}{$\begin{array}{l}\text { Первая группа } \\
\text { инвалидности }\end{array}$} & \multicolumn{2}{|c|}{$\begin{array}{l}\text { Вторая группа } \\
\text { инвалидности }\end{array}$} & \multicolumn{2}{|c|}{$\begin{array}{l}\text { Третья группа } \\
\text { инвалидности }\end{array}$} \\
\hline & & a6c. & $\%$ & a6c. & $\%$ & a6c. & $\%$ \\
\hline 2014 & 557 & 191 & 34,4 & 184 & 33,0 & 182 & 32,6 \\
\hline 2015 & 649 & 258 & 39,8 & 185 & 28,5 & 206 & 31,7 \\
\hline 2016 & 676 & 248 & 36,7 & 166 & 24,6 & 262 & 38,7 \\
\hline 2017 & 716 & 330 & 46,1 & 177 & 24,7 & 209 & 29,2 \\
\hline 2018 & 658 & 302 & 45,9 & 163 & 24,8 & 193 & 29,3 \\
\hline $\begin{array}{l}\text { Всего за пять } \\
\text { лет }\end{array}$ & 3256 & 1329 & 40,8 & 875 & 26,9 & 1052 & 32,3 \\
\hline
\end{tabular}

Таблица 6. Нозологическая структура первичной инвалидности вследствие психических расстройств среди взрослого населения Алтайского края в 2014-2018 гг.

\begin{tabular}{|c|c|c|c|c|c|c|c|c|c|}
\hline \multirow[t]{2}{*}{ Годы } & \multirow[t]{2}{*}{ Всего, абс. } & \multicolumn{2}{|c|}{$\begin{array}{l}\text { Органические, } \\
\text { включая } \\
\text { симптоматические, } \\
\text { психические } \\
\text { расстройства } \\
\text { (F00-F09) }\end{array}$} & \multicolumn{2}{|c|}{$\begin{array}{l}\text { Шизофрения, } \\
\text { шизотипические } \\
\text { и бредовые } \\
\text { расстройства } \\
\text { (F20-F29) }\end{array}$} & \multicolumn{2}{|c|}{$\begin{array}{l}\text { Умственная } \\
\text { отсталость (F70-F79) }\end{array}$} & \multicolumn{2}{|c|}{ Прочие } \\
\hline & & abc. & $\%$ & abc. & $\%$ & a6c. & $\%$ & aбc. & $\%$ \\
\hline 2014 & 557 & 364 & 65,4 & 164 & 29,4 & 28 & 5,0 & 1 & 0,2 \\
\hline 2015 & 649 & 456 & 70,3 & 167 & 25,7 & 25 & 3,9 & 1 & 0,1 \\
\hline 2016 & 676 & 453 & 67,0 & 169 & 25,0 & 54 & 8,0 & 0 & 0 \\
\hline 2017 & 716 & 515 & 71,9 & 166 & 23,2 & 30 & 4,2 & 5 & 0,7 \\
\hline 2018 & 658 & 512 & 77,8 & 124 & 18,9 & 22 & 3,3 & 0 & 0 \\
\hline $\begin{array}{l}\text { Всего за пять } \\
\text { лет }\end{array}$ & 3256 & 2300 & 70,6 & 790 & 24,3 & 159 & 4,9 & 7 & 0,2 \\
\hline
\end{tabular}

Исследование показало, что среди граждан в возрасте 18 лет и старше, впервые признанных инвалидами вследствие психических расстройств, стабильно преобладают городские жители (табл. 2).

Уровень первичной инвалидности городских жителей превышает уровень инвалидности сельских жителей и составил в 2014 г.- 3,2 (в сельской местности 2,6) на 10000 соответствующего населения, в 2015 г.— 4,0 и 2,6, в 2016 г.- 3,9 и 3,1, в 2017 г.- 4,2 и 3,4, в 2018 г.3,9 и 3,1 на 10000 соответствующего населения.

Из таблицы 3 следует, что среди граждан в возрасте 18 лет и старше, впервые признанных инвалидами вследствие психических расстройств, первое место стабильно занимает возрастная группа старше 55 лет (ж) и 60 лет (м), в целом за пять лет доля инвалидов этого возраста составила 54,8\%, второе место - инвалиды в возрасте 
от 18 до 44 лет, третье место - инвалиды от 45 до 54 лет (ж) и от 45 до 59 лет (м). В динамике имеется тенденция к снижению доли инвалидов молодого возраста (от 18 до 44 лет) с 35,9\% в 2014 г. до 21,4\% в 2018 г., а также инвалидов в возрасте от 45 до 54 лет (ж), от 45 до 59 лет (м) с $21,5 \%$ в 2014 г. до 14,6\% в 2018 г. и увеличению удельного веса инвалидов от 55 лет (ж) и 60 лет (м) и старше с $42,6 \%$ в 2014 г. до $64,0 \%$ в 2018 г.

Как видно на рисунке 1, наибольшие показатели уровня первичной инвалидности вследствие психических расстройств установлены в возрастной группе от 55 лет (ж) и 60 лет (м) и старше со стабильной тенденцией к увеличению - с 4,0 в 2014 г. до 6,6 на 10000 населения соответствующего возраста в 2018 г. Наименьшие показатели уровня регистрировались в возрастной группе молодого возраста от 18 до 44 лет с тенденцией к снижению с 2,2 в 2014 г. до 1,7 на 10000 соответствующего населения в 2018 г. В возрастной группе от 45 до 54 лет (ж), от 45 до 59 лет (м) уровень первичной инвалидности варьировал незначительно - с 2,9 в 2014 г. до 2,6 на 10000 населения соответствующего возраста в 2018 г.

Из таблицы 4 следует, что среди граждан в возрасте 18 лет и старше, впервые признанных инвалидами вследствие психических расстройств, в 2014 г. и 2016 г. преобладали мужчины (53,7\% и 51,2\% соответственно), в 2015 г. и 2017-2018 гг.- преобладали женщины (53,8\%, 51,5\%, 55,6\% соответственно).

Изучение динамики уровня первичной инвалидности вследствие психических расстройств среди граждан в возрасте 18 лет и старше в зависимости от пола показало преобладание уровня инвалидности среди мужского населения, за исключением 2018 г. (в 2014 г.— 3,5, в 2015 г.-3,5, в 2016 г.— 4, 1, в 2017 г.4,1 на 10000 соответствующего населения). Уровень инвалидности среди женского населения, несмотря на более низкие показатели, имел тенденцию к увеличению и составлял в 2014 г.- 2,4, в 2015 г.- 3,3, в 2016 г.- 3,2, в 2017 г.- 3,6 на 10000 соответствующего населения. В 2018 г. уровень инвалидности среди мужчин составил 3,5, среди женщин - 3,6 на 10000 соответствующего населения.

Из таблицы 5 следует, что в структуре первичной инвалидности вследствие психических расстройств преобладает первая группа инвалидности, доля инвалидов с этой группой составила за пять лет 40,8\%. В динамике имеет место тенденция к увеличению удельного веса первой группы инвалидности с 34,4\% в 2014 г. до 45,9\% в 2018 г. преимущественно за счет возрастной группы старше 55 лет (ж) и 60 лет (м). Третья группа инвалидности в структуре первичной инвалидности вследствие психических расстройств за пять лет составила 32,3\%, в динамике имеется тенденция к уменьшению доли инвалидов с третьей группой с 32,6\% в 2014 г. до 29,3\% в 2018 г. Наименьшую долю составляла вторая группа инвалидности - за пятилетний период 26,9\% с тенденцией к снижению с 33,0\% в 2014 г. до 24,8\% в 2018 г.

Исследование показало, что в молодом возрасте от 18 до 44 лет и в возрастной группе от 45 до 54 лет (ж), от 45 до 59 лет (м) чаще устанавливалась третья группа инвалидности. Так, в возрасте от 18 до 44 лет доля инвалидов третьей группы составила в 2014 г.- 49,5\%, в 2015 г.57,4\%, в 2016 г.- 68,7\%, в 2017 г.- 71,5\%, в 2018 г.70,9\%; в возрасте от 45 до 54 лет (ж), от 45 до 59 лет (м) составила в 2014 г.- 51,7\%, в 2015 г.- 57,3\%, в 2016 г.$57,3 \%$, в 2017 г.-50,0\%, в 2018 г.- 58,3\%. В возрастной группе от 55 лет (ж) и 60 лет (м) и старше чаще устанавливалась первая группа инвалидности (в 2014 г.- 73,0\%, в 2015 г.- 68,7\%, в 2016 г.- 69,6\%, в 2017 г.- 72,5\%, в 2018 г.- 69,4\%). В динамике имеется тенденция к увеличению доли инвалидов с третьей группой среди лиц в возрасте от 18 до 44 лет.

Как видно из таблицы 6, в нозологической структуре первичной инвалидности вследствие психических расстройств среди взрослого населения Алтайского края в 2014-2018 гг. первое место занимали органические, включая симптоматические, психические расстройства (70,6\% за пять лет) с тенденцией к увеличению с 65,4\% в 2014 г. до 77,8\% в 2018 г., второе место - шизофрения, шизотипические и бредовые расстройства $(24,3 \%$ за пять лет) с тенденцией к уменьшению с 29,4\% в 2014 г. до 18,9\% в 2018 г., третье место - умственная отсталость (4,9\% за пять лет).

\section{Зак^ючение}

Проведенный анализ показал, что за период с 2014 по 2018 г. в Алтайском крае имеется тенденция к увеличению доли инвалидов вследствие психических расстройств среди общего числа впервые признанных инвалидами в возрасте 18 лет и старше. Уровень первичной инвалидности граждан взрослого населения вследствие психических расстройств в крае превышает аналогичные показатели по Сибирскому Федеральному округу и Российской Федерации, и имеет тенденцию к увеличению. Среди граждан, впервые признанных инвалидами вследствие психических расстройств, преобладают городские жители (в среднем более 60,0\%), по полу - женщины (в среднем более 50,0\%). Распределение впервые признанных инвалидами граждан вследствие психических расстройств по возрасту показало преобладание возрастной группы от 55 лет (ж) и 60 лет (м) и старше. Уровень инвалидности в данной возрастной группе имеет тенденцию к увеличению. Результаты 
исследования показали, что гражданам с психическими расстройствами чаще устанавливалась первая группа инвалидности преимущественно в возрасте от 55 лет (ж) и 60 лет (м) и старше. В нозологической структуре первичной инвалидности вследствие психических расстройств значительно преобладали органические психические расстройства (F00-F09) и составляли в среднем более $70,0 \%$.

\section{ЛИТЕРАТУРА}

1. Гришина, Л.П. Анализ инвалидности взрослого населения по обращаемости в бюро медико-социальной экспертизы в Российской Федерации // Медико-социальная экспертиза и реабилитация. — 2008. — № 1.—C. 28-31.

2. Давлетшин, И. 3. Медико-социальная экспертиза при шизофрении и умственной отсталости. Медицинская практика. Информационный сайт для специалистов в области медицины. Выпуск 6/13/12.

3. Зверев, К. В. Структура и уровень первичной инвалидности взрослого населения по классам болезней в Российской Федерации в $2003-2006$ гг. // Медико-социальная экспертиза и реабилитация. — 2008. — № 1.—C. 22-24.

4. Основные показатели первичной инвалидности взрослого населения в Российской Федерации в 2014 году (статистический сборник) / под ред.д.м.н., проф. Л.П. Гришиной. - М.-2015. - 217 с.

5. Основные показатели первичной инвалидности взрослого населения в Российской Федерации в 2015 году (статистический сборник) / под ред.д.м.н., проф. Л. П. Гришиной. - М.-2016. - 220 с.

6. Основные показатели первичной инвалидности взрослого населения в Российской Федерации в 2016 году (статистический сборник) / под ред.д.м.н., проф. Л.П. Гришиной.— М.-2017.-263 с.

7. Основные показатели первичной инвалидности взрослого населения в Российской Федерации в 2017 году (статистический сборник) / под ред.д.м.н. М. А. Дымочки. - М.- 2018. - 265 с.

8. Основные показатели первичной инвалидности взрослого населения в Российской Федерации в 2018 году (статистический сборник) / под ред.д.м.н. М. А. Дымочки.- М.-2019.-268 с.

9. Пузин, С. Н. Медико-социальная экспертиза: состояние, перспективы / С. Н. Пузин, С. С. Меметов, Н. П. Шаркунов // Вестник Всероссийского общества специалистов по медико-социальной экспертизе, реабилитации и реабилитационной индустрии. - 2018. - № 2. - С. 7-13.

10. Состояние здоровья населения и деятельность здравоохранения Алтайского края в 2015 году. Статистический сборник. Часть 2. — Барнаул. - 2016. 455 c.

11. Состояние здоровья населения и деятельность здравоохранения Алтайского края в 2016 году. Статистический сборник. Часть 2.— Барнаул.— 2017.— $443 \mathrm{c}$.

12. Состояние здоровья населения и деятельность здравоохранения Алтайского края в 2017 году. Статистический сборник. Часть 2. — Барнаул. — 2018. 437 c.

13. Состояние здоровья населения и деятельность здравоохранения Алтайского края в 2018 году. Статистический сборник. Часть 2. — Барнаул. - 2019.$611 \mathrm{c.}$

14. Хритинин, Д.Ф.Современное состояние и пути совершенствования региональной службы психического здоровья / Д.Ф. Хритинин, В.3. Кучеренко, М. А. Некрасов. - M. - 2008.

15. Kickbusch I., Gleicher D. Стратегическое руководство в интересах здоровья в XXI веке: исследование, проведенное для Европейского регионального бюро B03.- 2014. - $135 \mathrm{c}$. 